\title{
Cerebrospinal fluid adenosine deaminase activity: A complimentary tool in the early diagnosis of tuberculous meningitis Rajpal S Kashyap ${ }^{1}$, Rani P Kainthla1 ${ }^{1}$ Anju V Mudaliar ${ }^{1}$, Hemant J Purohit ${ }^{2}$, Girdhar M Taori ${ }^{1}$ and Hatim F Daginawala*1
}

\author{
Address: ${ }^{1}$ Biochemistry Research Laboratory, Central India Institute of Medical Sciences, 88/2 Bajaj Nagar, Nagpur-440010, India and \\ 2Environmental Genomics Unit, NEERI, Nehru Marg, Nagpur-440020, India \\ Email: Rajpal S Kashyap - raj_ciims@rediffmail.com; Rani P Kainthla - poonam_ciims@yahoo.com; \\ Anju V Mudaliar - anju_mudaliar@rediffmail.com; Hemant J Purohit - hemantdrd@hotmail.com; \\ Girdhar M Taori - taorigm_ciims@yahoo.co.in; Hatim F Daginawala* - hfd_ciims@rediffmail.com \\ * Corresponding author
}

Published: 30 March 2006

Cerebrospinal Fluid Research2006, 3:5 doi:10.1186/1743-8454-3-5

This article is available from: http://www.cerebrospinalfluidresearch.com/content/3/l/5

(C) 2006Kashyap et al; licensee BioMed Central Ltd.

This is an Open Access article distributed under the terms of the Creative Commons Attribution License (http://creativecommons.org/licenses/by/2.0), which permits unrestricted use, distribution, and reproduction in any medium, provided the original work is properly cited.
Received: 25 August 2005

Accepted: 30 March 2006

\begin{abstract}
Background: Tuberculous meningitis (TBM) is the commonest form of neurotuberculosis caused by Mycobacterium tuberculosis bacilli (MTB). The diagnosis of TBM is often difficult. A reliable, costeffective and rapid diagnostic test, which can be performed in any standard pathology laboratory, could be of help in the diagnosis of TBM. In the present study we measured the adenosine deaminase (ADA) activity in cerebrospinal fluid (CSF) of TBM and non-TBM patients.
\end{abstract}

Method: ADA activity in CSF was determined according to a method based on the Berthlot reaction, which is the formation of a colored indophenol complex from ammonia liberated from adenosine, and quantified spectrophotometrically.

Results: The CSF ADA activity from TBM patients was compared with CSF ADA from non-TBM infectious meningitis patients, and from patients with non-infectious neurological disorders. The mean CSF ADA activity was found to be significantly higher in CSF of TBM patients, $\mid 4.31 \pm 3.87$ (2.99-26.94), mean \pm SD with range, than in the CSF from non-TBM infectious meningitis, $9.25 \pm$ $2.14(4.99-13.96)$ and from the non-infectious neurological disorders group, $2.7 \mathrm{I} \pm 1.96(0.00$ 7.68), $P<0.000 \mathrm{I}$ for both comparisons. A cut-off value of II.39 U/L/min for the TBM patients was calculated from the mean + SD of the non-TBM patients. The ADA test gave a sensitivity of $82 \%$ and a specificity of $83 \%$ for infectious TBM when this cut-off value was used.

Conclusion: This study demonstrated that ADA activity in the CSF of TBM patients, using a cutoff value $11.39 \mathrm{U} / \mathrm{L} / \mathrm{min}$, can be useful for the early differential diagnosis of TBM. This test can be performed in any pathology laboratory where more sophisticated methods are not available.

\section{Background}

Tuberculous meningitis (TBM) is the infection of the meninges caused by Mycobacterium tuberculosis (MTB). The diagnosis of TBM is complicated as it causes various clini- cal manifestations, which overlap with those of other chronic diseases of the central nervous system (CNS) such as viral and pyogenic meningitis [1]. The initiation of antiTB medication in suspected TBM patients can often be 
Table I: The mean ADA activity (with range) in the CSF of TBM patients $(n=1$ I $)$, non-TBM infectious meningitis patients $(n=60)$ and control patients with non-infectious neurological disorders $(n=104)$. The data are expressed as mean \pm SD

\begin{tabular}{|c|c|c|}
\hline Patient groups & ADA activity (U/L/min) Mean \pm SD & Range \\
\hline I. Tuberculous Meningitis $(n=1 \mid 7)$ & $|4.3| \pm 3.87$ & $2.99-26.94$ \\
\hline Culture positive $(n=27)$ & $17.67 \pm 4.18$ & $9.01-26.94$ \\
\hline Clinically suspected $(n=90)$ & $13.29 \pm 3.16$ & $2.99-21.02$ \\
\hline 2. Non TВM infectious meningitis $(n=60)$ & $9.25 \pm 2.14$ & $4.99-13.96$ \\
\hline Pyogenic meningitis $(n=4 I)$ & $10.11 \pm 1.99$ & $5.11-13.96$ \\
\hline Viral meningitis $(n=19)$ & $7.39 \pm 0.93$ & $4.99-9.00$ \\
\hline 3. Non-infectious neurological disorders $(n=104)$ & $2.71 \pm 1.96$ & $0.00-7.68$ \\
\hline Headache $(n=32)$ & $0.98 \pm 0.19$ & $0.11-1.20$ \\
\hline Stroke $(n=29)$ & $4.18 \pm 1.19$ & $1.92-5.83$ \\
\hline Venous sinus thrombosis $(n=13)$ & $1.82-4.12$ & \\
\hline Guillian-Barré syndrome $(n=12)$ & $5.38 \pm 2.16$ & $2.63-7.68$ \\
\hline Epilepsy $(n=6)$ & $2.36 \pm 0.79$ & $1.01-3.18$ \\
\hline Other neurological disorders $(n=12)$ & $1.18 \pm 0.47$ & $0.5-1.87$ \\
\hline
\end{tabular}

delayed because of a lack of confidence in the presently available laboratory tests $[2,3]$. Most of the tests developed for the early diagnosis of TBM are not sensitive [4] and although some other tests are useful, they may not be affordable for routine use [5,6]. A reliable and rapid diagnostic test, which can be performed in any standard pathology laboratory, could be of help in diagnosis of TBM.

Adenosine deaminase (ADA) is an enzyme that catalyzes the deamination of adenosine, forming inosine in the process [7]. The chief physiological function of ADA is related to lymphocytic proliferation and differentiation [8]. As a marker of cellular immunity, activity is found to be elevated in those diseases in which there is a cell-mediated immune response [9]. Numerous previous studies have demonstrated that CSF-ADA estimation is useful in the diagnosis of TBM and can differentiate TBM from normal subjects or from patients with other neurological disorders [10-12]. However, the results were variable and one study has shown that ADA is of limited value as it was also raised in other types of meningitis especially pyogenic meningitis [13]. In this paper we describe a prospective study to evaluate the reliability of ADA activity in the CSF for diagnosis in patients with TBM, patients with nonTBM infectious meningitis and patients with non-infectious neurological disease. A cut-off value for CSF ADA activity has been calculated for the diagnosis of TBM.

\section{Materials and methods \\ Patients}

A total of 281 patients $(\mathrm{TBM}=117$, pyogenic meningitis = 41 , viral meningitis $=19$, and 104 control subjects with non-infectious neurological disorders) were included in the present study. Patients included in the study were those admitted to the Neurology Department of Central India Institute of Medical sciences (CIIMS) between $1^{\text {st }}$ January 2003 and the end of February 2004. All patients were above the age of 20 years. CSF samples for ADA estimations and other tests were obtained before starting any treatment in all cases of neurological disorders including viral, bacterial, and mycobacterial meningitis. The Institutional Ethics Committee of Central India Institute of Medical Sciences, Nagpur, approved the study.

\section{Patient Groups (Table I)}

I. Tuberculosis Meningitis patients $(n=1 / 7$ )

A: Clinically confirmed cases $(n=27)$ : Confirmed by the presence of Mycobacterium tuberculosis in CSF by staining and/or culture.

B: Clinically suspected patients $(n=90)$ : This group had negative cultures with all of the following observations:

a: Sub-acute or chronic fever with features of meningeal irritation such as headache, neck stiffness and vomiting, with or without other features of CNS involvement.

b: CSF samples showing raised protein levels, and/or decreased glucose (CSF: blood glucose ratio $<0.5$ ), and/or pleocytosis with lymphocytic predominance.

c: Good clinical response to antituberculous drugs.

\section{Non-TBM infectious pyogenic and viral meningitis patients $(n=$} 60)

A: Pyogenic meningitis $(n=41)$ : Confirmed cases $(n=9)$ : Presence of pathogenic bacteria in CSF by staining and/or culture.

Clinically suspected $(\mathrm{n}=32)$ : This group included the culture negative cases with all of the following observations:

a: Fever and/or signs of meningeal irritation (patients who have undergone cranial surgery to treat tumor(s), stroke, or head injury and who have received antibiotics), or high 


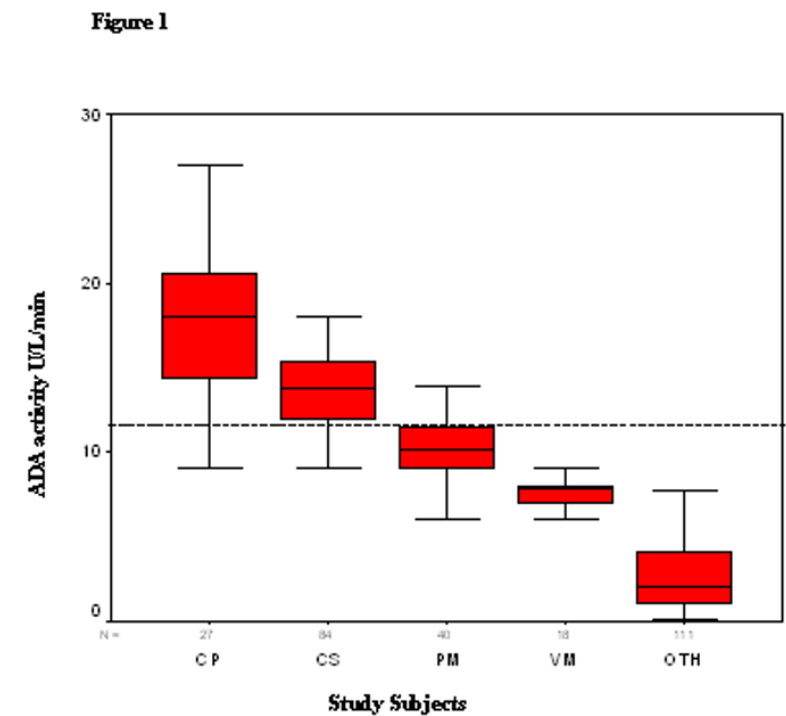

\section{Figure I}

Box plots of CSF ADA activity in TBM (CP-culture positive; CS-clinically suspected), non-TBM infectious meningitis (PMpyogenic meningitis; VM-viral meningitis) and control group of non-infectious neurological disorders (OTH). The plots show the $90^{\text {th }}$ percentile (bars), $75^{\text {th }}$ and $25^{\text {th }}$ percentile (box) and median (bar in box). $N=$ numbers of individuals in each group. Dashed line represents the calculated ADA cut off value.

fever and/or signs of meningeal irritation with or without CNS manifestations (patients who received broad-spectrum antibiotics).

b: CSF findings showing increased proteins, decreased glucose (CSF: blood glucose ratio <0.2), and/or pleocytosis with a predominance of polymorphonuclear cells.

c: Good clinical response to broad-spectrum antibiotics.

B: Viral meningitis patients $(n=19)$ : This group includes suspected patients with the following observations:

a: Acute onset of fever and symptoms and signs of meningeal irritation.

b: CSF samples showing mild increase in protein, glucose often normal and pleocytosis, predominantly lymphocytic.

c: No clinical evidence for extra cranial tuberculosis.

\section{Non-infectious neurological disorders group $(n=104)$}

All other patients who had no evidence of CNS or extra CNS bacterial or viral infections were grouped in the non- infectious/control group. Patients included in this group had chronic intractable headache, status epilepticus, stroke and others disorders (Table 1).

\section{Sample collection}

CSF samples were collected by standard lumbar puncture. Approximately $3 \mathrm{ml}$ of CSF was obtained; $2 \mathrm{ml}$ of CSF was used for total and differential cell count, biochemistry, and smear for Gram's, India ink, and acid fast bacilli (AFB) staining and the remaining CSF was used for ADA estimation. All the samples were stored at $4{ }^{\circ} \mathrm{C}$ until further analysis.

\section{ADA activity measurement}

ADA activity in CSF was determined at $37^{\circ} \mathrm{C}$ according to the method of Guisti and Galanti [14] based on the Berthlot reaction, that is the formation of colored indophenol complex from ammonia liberated from adenosine and quantified spectrphotometrically (U.V.Visible spectrophotometer.Remi.Model C-24). One unit of ADA is defined as the amount of enzyme required to release 1 mmol of ammonia/min from adenosine at standard assay conditions. Results were expressed as units per litre per minute $(\mathrm{U} / \mathrm{L} / \mathrm{min})$. The assays were performed in triplicate and blind to the diagnosis.

\section{Data analysis}

Results are expressed as mean \pm SD with Range. To compare the mean ADA activity between the TBM, non-TBM infectious meningitis and non-infectious neurological disorders groups, the Kruskal Wallis test (non-parametric ANOVA) with the Dunnett post-test was used. A $P$ value less than 0.05 was considered significant. A cut off value of ADA activity for TBM patients was calculated from the mean plus SD of ADA activity in the non-TBM infectious meningitis group. The sensitivity (true positive rate) for the test was calculated as: [the number of samples in the TBM group with ADA activity $\geq($ mean+SD) of ADA activity in the non-TBM infectious meningitis group divided by the total number of samples in TBM group] $\times 100$. The specificity (true negative rate) for the test was calculated as: [the number of samples in non-TBM infectious meningitis group with ADA activity $<($ mean+SD) of ADA activity in the non-TBM infectious meningitis group divided by the total number of samples in non-TBM infectious meningitis group] $\times 100$.

\section{Results}

The total number of patients studied was 281 . Of these, 27 were confirmed for TBM, 90 were suspected for TBM, 60 had non-TBM infectious meningitis (pyogenic meningitis, 41, and viral meningitis, 19) and 104 had other CNS disorders. 
Table 2: The number and percentage of patients positive and negative for the CSF ADA test using the diagnostic cut-off value of $>$ I $1.39 \mathrm{U} / \mathrm{L} / \mathrm{min}$ for the TBM patients, the non-TBM infectious meningitis patients and the control group with non-infectious neurological disorders. The sensitivity of the test for positive diagnosis was $\mathbf{8 2} \%$ and the specificity was $\mathbf{8 3} \%$. The $\mathbf{9 5 \%}$ confidence interval for sensitivity is between $\mathbf{7 3 . 9}$ I and $\mathbf{9 0 . 1 9}$, while $95 \%$ confidence interval for specificity is between $\mathbf{7 7 . 6 7}$ and $\mathbf{8 8 . 9 9}$.

\begin{tabular}{|c|c|c|}
\hline Patient groups & $\begin{array}{c}\text { Number of patients with ADA activity } \\
\qquad>11.39 \mathrm{U} / \mathrm{L} / \mathrm{min}\end{array}$ & $\begin{array}{c}\text { Number of patients with ADA activity } \\
<11.39 \mathrm{U} / \mathrm{L} / \mathrm{min}\end{array}$ \\
\hline I. Tuberculous Meningitis $(n=117)$ & $96(82 \%)$ & $21(18 \%)$ \\
\hline Culture positive $(n=27)$ & $26(96 \%)$ & I (4\%) \\
\hline Clinically suspected $(n=90)$ & 70 (78\%) & $20(22 \%)$ \\
\hline 2. Non-TBM infectious meningitis $(n=60)$ & $10(17 \%)$ & $50(83 \%)$ \\
\hline Pyogenic meningitis $(n=4 I)$ & $10(24 \%)$ & $31(76 \%)$ \\
\hline Viral meningitis $(n=19)$ & $0(0 \%)$ & $19(100 \%)$ \\
\hline 3. Non-infectious neurological disorders $(n=104)$ & 0 & $104(100 \%)$ \\
\hline Headache $(n=32)$ & 0 & $32(100 \%)$ \\
\hline Stroke $(n=29)$ & 0 & $29(100 \%)$ \\
\hline Venous sinus thrombosis $(n=13)$ & 0 & $13(100 \%)$ \\
\hline Guillian-Barré syndrome $(n=12)$ & 0 & $12(100 \%)$ \\
\hline Epilepsy (06) & 0 & $06(100 \%)$ \\
\hline Other neurological disorders $(n=12)$ & 0 & $12(100 \%)$ \\
\hline
\end{tabular}

Table 1 depicts the mean ADA activity in the CSF of different patient groups. The mean ADA activity in TBM patients was $14.31 \pm 3.87(2.99-26.94)$, significantly higher than the non-TBM infectious meningitis group, $9.25 \pm 2.14$ (4.99-13.96); $P<0.0001$, and also higher than the non-infectious neurological disorders group, $2.71 \pm 1.96(0.00-7.68) ; P<0.0001$. A significant difference in the mean ADA activity was noted also in the CSF of culture-positive TBM patients, $17.67 \pm 4.18$ (9.0126.94), when compared with the clinically suspected TBM patients, $13.29 \pm 3.16(2.99-21.02) ; P<0.0001$. The cut off value of the ADA activity for the diagnosis of TBM patients was, calculated as $9.25+2.14=11.39 \mathrm{U} / \mathrm{L} / \mathrm{min}$. Box plots of the ADA activity in the CSF of culture positive and clinically suspected TBM patients, non-TBM infectious meningitis and non-infectious neurological disorders groups are shown in Figure 1 , together with the $90^{\text {th }}$ percentile range, $75^{\text {th }}$ and $25^{\text {th }}$ percentiles.

Table 2 shows the number and percentage of patients in each group that fall above or below the cut-off value. Sensitivity in the TBM group was $96 \%$ (96\% of the culture positive samples were above the cut-off value) whereas it was only $78 \%$ in the clinically suspected group. In the non-TBM infectious meningitis group, $24 \%$ in the pyogenic meningitis group were above the cut-off value, but none of the viral meningitis samples were over the cut-off value. For the non-infectious neurological disorder group, none of the patients had ADA activity above the cut-off value. The sensitivity of the ADA test to differentiate between TBM and non-infectious meningitis was $82 \%$ and the specificity was $83 \%$ when the cut-off value of $11.39 \mathrm{U} / \mathrm{L} / \mathrm{min}$ was used. The $95 \%$ confidence interval for sensitivity was 90.19 (upper limit) and 73.91 (lower limit) while the $95 \%$ confidence interval for specifity was 88.99 (upper limit) and 77.67 (lower limit).

\section{Discussion}

TBM remains a major global health problem and even in developed countries there is a resurgence of tuberculous infection due to the growing number of people infected with human immunodeficiency virus (HIV) [15,16]. Early confirmatory diagnosis of TBM is difficult to establish because of its pleomorphic clinical presentation $[3,17]$. Delayed diagnosis and treatment may be associated with many serious CNS complications [18]. The most commonly used laboratory method for the definitive diagnosis of TBM is to demonstrate the presence of tubercle bacilli either by smear and/or culture. However, direct smear methods are often negative in CSF samples and culturing of MTB takes 4-6 weeks to show the growth $[19,20]$. Newer methods such as those involving the amplication of bacterial DNA by the PCR and comparable systems, are incompletely assessed and not available for widespread use in the developing countries. The sensitivity of the PCR technique varies from $33 \%$ to $90 \%$ and the specificity from $88 \%$ to $100 \%$ [21]. Various immunoassays such as antigen and/or antibody detection in CSF samples have been developed with variable sensitivities and specificities [2,9,10,22-24]. Hence, despite extensive work on TBM, only few diagnostic tests are available. Recently we have reported on a $30 \mathrm{kD}$ protein antigen comprising of antigen 85 complex in CSF of TBM patients by indirect ELISA method with a sensitivity of $89 \%$ and specificity of $97 \%$ [25].

ADA has been considered as a marker of cell-mediated immunity and its activity has been observed in various infections including TBM [9]. Considering that both 
humoral and cell-mediated immunity play an important role in TBM infection, it has been suggested that ADA activity in CSF may help differentiate TBM from non-TBM infectious meningitis and non-infectious neurological disorders, and this has been discussed earlier by various workers $[11,12,26]$.

In the present study we have calculated an ADA cut-off value of $11.39 \mathrm{U} / \mathrm{L} / \mathrm{min}$ in CSF for the diagnosis of TBM infection. Using this we have demonstrated a sensitivity of $96 \%$ and $78 \%$ in the CSF of culture-positive and clinically-diagnosed TBM patients, respectively. False positive results were noted in $24 \%$ of pyogenic meningitis cases. No other control group gave false positive results.

Earlier, various workers have reported the reliability of CSF ADA activity in TBM patients using different cut off values. Pettersson et al. reported sensitivity of $100 \%$ and specificity of $99 \%$ when a cut off value of $20 \mathrm{U} / \mathrm{L} / \mathrm{min}$ was used, but in that study there were only three enrolled tuberculous meningitis patients [12]. Baro et al proposed a cut off value of $6.5 \mathrm{U} / \mathrm{L} / \mathrm{min}$ and showed sensitivity of $83.3 \%$ and specificity of $85.3 \%$ [11]. However, this study used only 12 cases of TBM patients, and pyogenic and viral meningitis were not distinguished from the group with other central nervous system diseases. Similarly increased CSF ADA levels have been reported in childhood TBM with adverse neurological outcome [27]. However, Gambhir et al reported a low sensitivity of $44 \%$ and specificity of $75 \%$ for ADA test with a cut off value $8 \mathrm{IU} / \mathrm{L} /$ min, which showed overlap between TBM and non-TBM patients, especially for infectious neurological disorders like pyogenic meningitis [28].

The laboratory method for measuring ADA is inexpensive, relatively simple to perform and can also be adapted to an autoanalyser. It may thus be useful in laboratories with limited resources, especially in underdeveloped and developing countries like India where the incidence of tuberculosis is very high and where, despite extensive work on pulmonary and extra pulmonary tuberculosis, only a few diagnostic kits are available for tuberculous meningitis.

\section{Conclusion}

In conclusion, the determination of ADA activity in CSF of TBM patients using cut off value of $11.39 \mathrm{U} / \mathrm{L} / \mathrm{min}$ can be useful for the early differential diagnosis of TBM and it is cost effective. However CSF ADA should be interpreted judiciously in the light of the patient's clinical condition and CSF characteristics since there is a wide range of CSF ADA activity in TBM. In addition, there is overlap with ADA activity in some pyogenic meningitis patients. Overall our study suggests that measurement of ADA activity in CSF of TBM patients with a cut off value of $11.39 \mathrm{U} / \mathrm{L} / \mathrm{min}$ can be useful as a supporting test for the differential diagnosis.

\section{Declaration of competing interests}

The author(s) declare that they have no competing interests.

\section{Authors' contributions}

RSK carried out the study design, data collection, statistical analysis, data interpretation, literature search, and manuscript preparation; RPK and AVM assisted in data analysis collection; HJP participated in the preparation of the manuscript, data interpretation, and study design; GMT provided assistance in preparation of the manuscript, data interpretation, study design, and funds collection; and HFD supervised the study design, statistical analysis, data interpretation, manuscript preparation, and literature search. All authors have read and approved the final version of the manuscript.

\section{Acknowledgements}

We thank Rashmi.N.Mishra for assistance in statistical analysis.

\section{References}

I. Kashyap RS, Biswas SK, Agarwal N, Chandak N, Purohit HJ, Taori GM, Daginawala HF: Significance of 30 KD protein marker as diagnostic marker in CSF of tuberculous meningitis. Ann Ind Acad Neurl 200I, 4:197-201.

2. Kashyap RS, Kainthla RP, Purohit HJ, Chandak N, Agarwal N, Taori GM, Daginawala HF: Rapid diagnosis of tuberculous meningitis using the simple Dot ELISA method. Med Sci Monit 2003, 9:123-126.

3. Kashyap RS, Biswas SK, Purohit HJ, Chandak N, Agarwal N, Taori GM, Daginawala HF: Application of Mancini technique as a diagnostic test in CSF of tuberculous meningitis patients. Med Sci Monit 2002, 8:95-98.

4. Kilpatrick ME, Girgis NI, Yassin MW, Abu el Ella AA: Tuberculous meningitis - clinical and laboratory review of 100 patients. J Hyg (London) 1986, 96:23I-238.

5. Kashyap RS, Kainthla RP, Satpute RM, Agarwal NP, Chandak NH, Purohit HJ, Taori GM, Daginawala HF: Differential diagnosis of tuberculous meningitis from partially treated cases of pyogenic meningitis by cell ELISA. BMC Neurology 2004, 4: 16 .

6. Radhakrishnan VV, Mathai A: Detection of Mycobacterium tuberculosis antigen 5 in cerebrospinal fluid by inhibition ELISA and its diagnostic potential in tuberculous meningitis. J Infect Dis 1991, 163:650-652.

7. Fox $\mathrm{IH}$, Kelly $\mathrm{WN}$ : The role of adenosine deaminase and 2'deoxyadensoine in mammalian cells. Ann Rev Biochem 1978, 47:655-686.

8. Erel O, Kocyigit A, Gurel MS, Bulut V, Seyrek A, et al.: Adenosine Deaminase activities in sera, lymphocytes and granulocytes in patients with cutaneous Leishmaniasis. Mem Inst Oswaldo Cruz, Rio de Janeiro 1998, 93:49I-494.

9. Galanti B, Nardiello S, Russo M, Fiorentino F: Increased lymphocyte adenosine deaminase in typhoid fever. Scand J Infect Dis 198I, I 3:47-50.

10. Prasad R, Kumar A, Khanna BK, Mukerji PK, Agarwal SK, Kumar A, Srivastava VM: Adenosine deaminase activity in cerebro-spinal fluid for diagnosis of tuberculous meningitis. Ind J Tub |991, 38:99-102.

II. Baro M, Acevedo L, Lagos ME: Usefulness of adenosine deaminase determination in cerebrospinal fluid for the diagnosis of meningeal tuberculosis; 4 years experience at a public hospital. Rev Med Chill 1996, I 24:319-326.

12. Pettersson T, Klockars M, Weber TH: Diagnostic value of cerebrospinal fluid adenosine deaminase determination. Scand J Infect Dis 1991, 23:97-100. 
13. Corral I, Quereda C, Navas E, Martin-Davila P, Perez-Elias MJ, Casado JL, Pintado V, Cobo J, Pallares E, Rubi J, Moreno S: Adenosine deaminase activity in cerebrospinal fluid of HIV- infected patients: limited value for diagnosis of tuberculous meningitis. Eur J Clin Microbiol Infect Dis 2004, 23:47I-476.

14. Guisti G, Galanti B: Adenosine deaminase: colorimetric method. In Methods of Enzymatic Analysis 5th edition. Edited by: Bergmeyer HU. Weinheim (Germany): Verlag Chemie; 1984:3 I 5-323.

15. Horner PJ, Moss FM: Tuberculosis in HIV infection. Int J STD AIDS 199|, 2:162-7.

16. Selwyn PA: Tuberculosis in the AIDS era: A new threat from an old disease. NY State J Med |991, 91:233-235.

17. Katti MK: Assessment of antibody responses to antigens of Mycobacterium tuberculosis and Cysticercus cellulosae in cerebrospinal fluid of chronic meningitis patients for definitive diagnosis as TBM/NCC by passive hemagglutination and immunoblot assays. FEMS Immunol Med Microbiol 2002, 33:57-6I.

18. Kennedy DH, Fallon RJ: Tuberculous meningitis. JAMA 1979 , 24I:264-268.

19. Thwaites G, Chau TT, Mai NT, Drobniewski F, McAdam K, Farrar J: Tuberculous meningitis. J Neurol Neurosurg Psychiatry 2000, 68:289-299.

20. Mathai A, Radhakrishnan VV, Sarada C, George SM: Detection of heat stable mycobacterial antigen in cerebrospinal fluid by Dot-Immunobinding assay. Neurol India 2003, 5 I:52-54.

21. Nakajima H, Hatamura T, Ikemoto T, Ueda K, Nakagawa T, Shimizu $\mathrm{A}$ : Evolution of the polymerase chain reaction in the diagnosis of TBM. Rinsho Byori 1995, 43:843-846.

22. Watt G, Zaraspe G, Bautista S, Laughlin LW: Rapid diagnosis of tuberculous meningitis by using an enzyme linked immunosorbent assay to detect mycobacterial antigen and antibody in cerebrospinal fluid. J Infect Dis 1988, 158:68I-686.

23. Kadival GV, Kameswaran M, Doshi R, Todiwala SS, Samuel AM: Detection of antibodies to defined $M$. tuberculosis antigen ( $38 \mathrm{Kda})$ in cerebrospinal fluid of patients with tuberculous meningitis. Zentralbl Bakteriol 1994, 281:95-I0I.

24. Krambovitis E, Mclllmurray MB, Lock PE, Hendrickse W, Holzel H: Rapid diagnosis of tuberculous meningitis by latex particle agglutination. Lancet 1984, 2:|229-|23|

25. Kashyap RS, Dobos KM, Belisle JT, Purohit HJ, Chandak NH, Taori GM, Daginawala HF: Demonstration of components of antigen 85 complex in CSF of Tuberculous meningitis patients. Clin Diagn Lab Immunol 2005, I 2:752-758.

26. Blake J, Berman P: The use of adenosine deaminase assays in the diagnosis of tuberculosis. S Afr Med ] 1982, 62:|9-2|.

27. Jakka S, Veena S, Rao ARM, Eisenhut M: Cerebrospinal adenosine deaminase levels and adverse neurological outcome in pediatric tuberculous meningitis. Infection 2005, 33:264-266.

28. Gambhir IS, Mehta M, Singh DS, Khanna HD: Evaluation of CSF adenosine deaminase activity in tubercular meningitis. J Assoc Physicians India 1999, 47: 192-194.

\section{Publish with Biomed Central and every scientist can read your work free of charge}

"BioMed Central will be the most significant development for disseminating the results of biomedical research in our lifetime. "

Sir Paul Nurse, Cancer Research UK

Your research papers will be:

- available free of charge to the entire biomedical community

- peer reviewed and published immediately upon acceptance

- cited in PubMed and archived on PubMed Central

- yours - you keep the copyright
BioMedcentral 